\title{
INFLUENCE OF ECOLOGICAL AND QUALITY CONCERNS ON THE ADOPTION INTENTION OF ENVIRONMENT-SMART AGRICULTURAL SYSTEMS
}

\author{
CHI, S. Y. - CHIEN, L.-H.* \\ Department of Applied Economics, National Chung Hsing University \\ 145 Xinda Rd., Taichung City 40227, Taiwan \\ *Corresponding author \\ e-mail: lhchien@nchu.edu.tw; phone: +886-4-2285-1541; fax: +886-4-2286-0255 \\ (Received $3^{\text {rd }}$ Aug 2021; accepted $28^{\text {th }}$ Oct 2021)
}

\begin{abstract}
Within the framework of the theory of planned behavior, this paper explores whether farmers who plant high-priced tea accept an alternative farming system out of concern for the environment and product quality. In total, 253 tea farmers in Taiwan was interviewed, and their data were analyzed using partial least squares structural equation modeling. Statistical results indicated that the environmental concerns and quality considerations of tea farmers influence their behavioral intentions toward the adoption of new technology systems. Other social and economic variables, such as government subsidies, professional counseling, organization promotion, and community network, also affect their decisionmaking intention. Farmers with heterogeneous expectations of the new farming system must be considered in these analytical strategies. Based on the respondents' attitudes, effective promotion and implementation can be designed more specifically to target farmers' adoption intention by addressing ecological and product quality concerns.
\end{abstract}

Keywords: decision analysis, theory of planned behavior, tea farming, heterogeneous expectations, behavioral intention

Abbreviations: ESA, environment-smart agriculture; EC, ecological concerns; QC, quality concerns; TPB, theory of planned behavior; IA, intention to adopt ESA; AT, attitude toward the behavior; SN, subjective norms; PBC, perceived behavioral control; PLS-SEM, partial least squares structural equation modeling; AVE, average variance extracted; HTMT, heterotrait-monotrait ratio; FIMIX-PLS, finite mixture partial least squares; AIC, Akaike's information criterion; BIC, Bayesian information criterion; CAIC, consistent Akaike's information criterion; MDL, minimum description length; LnL, loglikelihood; EN, entropy statistic

\section{Introduction}

Environmental conservation and effective resource allocation have encouraged farmers to adopt more environmentally friendly technologies, and the efficient promotion of these ideas is crucial for agricultural policymakers. Many studies have integrated market demand, technological progress, and environmental concern to persuade farmers to adapt to environmental changes through the application and promotion of ecologically intelligent agricultural technology systems that also support the economic goals of farm management (Lalani et al., 2016; Pretty, 2008; Thornton et al., 2018). Rahman (2018) proposed the environment-smart agriculture (ESA) concept to consider the introduction of environmentally friendly farming devices under existing farming systems to minimize negative effects on the management habits and existing benefits of the operators. An ESA system collects field information through sensing technology, intelligent machines, and other related equipment and subsequently performs cloud computing with large data transmission or creative control of an expert database (Rahman, 2018). The system improves the quality of agricultural products by 
enhancing the soil and water conditions of farms and reducing the harmful environmental and ecological effects of farm production (Zeweld et al., 2017).

Acceptance of a recommended ESA management plan implies that farmers must change their original experience-based management into an environmentally friendly expert information system, through which they can simultaneously conduct intensive commercial production and maintain a sustainable ecological business model (Lalani et al., 2016). Although ESA adoption has proven environmentally beneficial, ESA policies have yet to achieve desired results in terms of scale and long-term execution. Farmers are required to replant crops entirely or substantially convert existing farming systems and habits. The adoption of such drastic changes in production systems is difficult for small-scale farmers facing uncertain crop yields and inherent business risks (Rahman, 2018).

Many studies have applied econometric models to evaluate the implementation of similar smart agricultural systems, such as climate-smart agriculture; however, those studies have not explained why some farmers achieve less effective results when systems are implemented in areas with high potential for development (Osmond et al., 2015). Their estimations may be biased toward influential factors, creating confusion regarding actual behavioral intentions without accounting for the diverse of agricultural production.

Considerations and measures of whether the adoption of environmentally intelligent agricultural systems meets the needs of farms must be diversified. A comprehensive model describing a farmer's decision-making process requires information on adequate soil fertility levels and biomass production as well as farming practices, technology, finance, sales systems, and policies to achieve satisfactory results (Wall et al., 2013). Pannell et al. (2014) attempted to gauge framer perspectives on similar systems, arguing that farmers contemplating switching to a new system consider not only short-term economic benefits and cost concerns but also farm operations, such as training and system knowledge, the opinions of families and neighbors, pest management, the opportunity costs of crop rotation, public aid and regulations on the use of critical resources, interaction with local businesses, and financial and trade conditions. Therefore, by addressing these different dimensions and prioritizing farmers' decisions, an evaluation of their trade-offs and synergies warrants attention.

The establishment of ESA involves changes to the farming pattern by installing electronic sensors and equipment to collect and transmit farming data (Liao and $\mathrm{Xu}$, 2019). Therefore, investment in these facilities and provision of technical support as well as mutual trust between farmers and stakeholders are critical factors in the initial stage of new smart system implementation and in determining whether the farmers can adopt this technology and adapt successfully (Makate et al., 2019; Nkala et al., 2011; Westermann et al., 2018). Social capital, personal effectiveness, training, and perceived usefulness also play key roles in the decision to adopt sustainable practices (Zeweld et al., 2017). Lalani et al. (2017) and Grabowski and Kerr (2014) have argued that if insufficient resources or commitment are provided to farmers during the system start-up stage, a low adoption rate occurs in the field and planned targets are not achieved; an ESA strategy's effectiveness is then limited to small plots of land, which farmers eventually abandon.

Many studies have indicated that government subsidy policies are essential for promoting environmentally friendly farming systems and have suggested that if the government does not provide continual financial support, they risk operational 
instability as serious as that posed by natural environmental factors, leading to unsustainable agricultural systems and ineffectiveness throughout a region (Borges et al., 2014; Mittenzwei et al., 2017; Pannell et al., 2014). In addition, the farming systems of small-scale farms are highly heterogeneous, and the factors influencing decisionmaking behavior regarding ESA systems are complex (Makate et al., 2019).

Scholars have proposed that farmers' willingness to adopt a technology is affected by the following concerns: farmers' past behaviors, socioeconomic characteristics, farm characteristics, farmers' risk attitudes and information sources (Bamberg et al., 2003; Brown et al., 2018), organizational promotion (Lalani et al., 2016), membership in farmers' associations (Issa and Hamm, 2017), weather-based crop agroadvisories (Khatri-Chhetri et al., 2017), national agricultural policies and related economic incentives (Mittenzwei et al., 2017; Nkala et al., 2011; Pannell et al., 2014), and the effects of initiatives by nongovernmental organizations and consumer groups. Thus, psychological factors are essential in measuring and analyzing the factors influencing smallholders' adoption of sustainable business models and their participation in public policy. Selecting a farm with a willingness to participate in public policy is crucial for effectively promoting ESA operations and achieving consistent performance.

Daxini et al. (2019) reported that due to a lack of consideration of farmers' psychosocial responses and decision-making attitudes in policy planning, they may be less proactive in selecting environmentally beneficial technology in practical operation. Possible concerns for farmers are social pressure, peer influence, self-expectation, and the willingness to adopt (Borges and Oude Lansink, 2016). Ajzen (1991) and Madden et al. (1992) proposed the theory of planned behavior (TPB), suggesting that three independent facets influence the behavioral intention of individual decision-making, namely attitude, subjective norms (i.e., social pressure), and perceived behavioral control (the extent to which individuals can achieve their goals). The intentions and perceived behaviors of decision-makers are defined as the influencers of behavioral beliefs (equivalent to the driving factors of attitudes), normative beliefs (equivalent to the driving factors of subjective norms), and control beliefs (comparable to the driving factors of perceived behavioral control).

Studies have employed this model to assess farmers' decision-making on a range of agricultural technologies from social and psychological perspectives (Beedell and Rehman, 2000; Borges et al., 2014; García et al., 2012; Lalani et al., 2016; Senger et al., 2017b). This theory has been widely used to analyze farmer decision-making through the influence of their supporting behaviors and attitudes, subjective norms, and perceived behaviors (Senger et al., 2017a; Zeweld et al., 2017).

This study applied the TPB to present the potential behavioral intention in farmers' decisions to adopt new technology by considering these three facets. The sustainability concerns of environment and product quality are also considered to represent additional drivers of operational intents (Ciccullo et al., 2018). Farmers are concerned about production possibilities, social pressures, ability perceptions, and subsequent changes in their intent to adopt. Because new operating system adoption may be affected by the unobservable heterogeneity of the farmers, this study used finite mixture partial least squares (FIMIX-PLS) segmentation to categorize farmers with diverse ecological and product quality concerns. Figure 1 represents the base concept and analytical processes.

The objectives of this study were as follows: 1) to identify notable differences among farmers' intentions to adopt ESA, 2) to identify the effects of the three TPB structural factors of behavioral intention in terms of different ecological and product quality 
concerns, and 3) to analyze the characteristic effects of ecological factors and product quality concerns of farmers with different intentions.

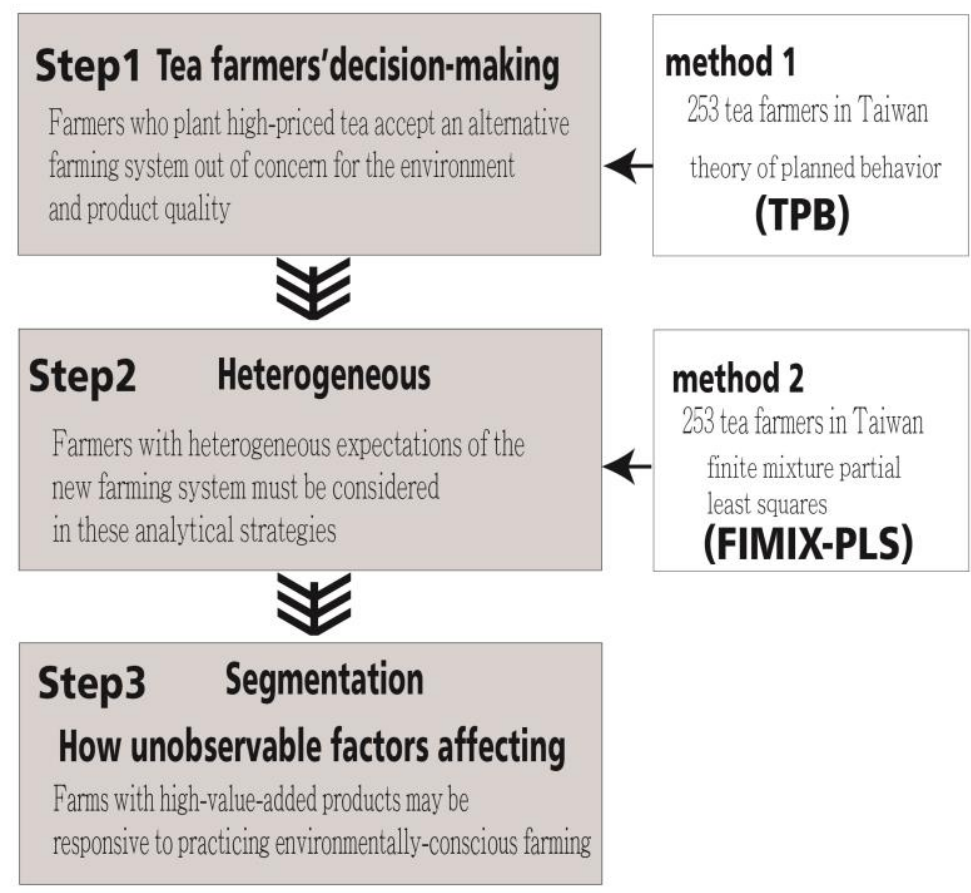

Figure 1. Base concept and analytical processes

\section{Materials and methods}

\section{Theory of planned behavior: an introduction}

According to the TPB, human social behavior is a reasonable stage process (Ajzen, 1991; Bamberg et al., 2003). The TPB maintains that behavior is psychologically driven by intentions (IA), which are influenced by the following three considerations: should I do this? (attitude, AT), do others think it should be done? (subjective norms, SN), and I think it can be done (perceived behavioral control, PBC). Perceived behavioral control emphasizes the ability of humans to control practices, and it may be an essential aspect of understanding farmers' agricultural decisions. Therefore, the role of behavioral intention in decision-making behavior is integrated in the TPB architecture through the consideration of perceived behavioral control (Lee et al., 2016; Madden et al., 1992; Mahindarathne and Gunaratne, 2015).

TPB has been widely used to understand farmers' decision-making and adoption behaviors in different agricultural areas. Policymakers can determine the role of intentions by grasping the underlying psychological factors that influence farmers' beliefs regarding the adoption of an ESA system (Borges et al., 2014; Lalani et al., 2016; Senger et al., 2017a, b; Zeweld et al., 2017). Research results have demonstrated that farmers' attitudes toward increasing production, reducing labor input, improving soil quality, and reducing critical cognitive drivers are the most influential factors affecting intent, in addition to social pressure and the opinions of family.

Attitudes are derived from an assessment of behavioral beliefs and their outcomes. Subjective norms originate from normative beliefs, which are formed by the normative 
expectations and adherence motives of the subject. This study proposes that ecological and product quality concerns affect a farmer's farming philosophy. Perceived behavioral control stems from controlling beliefs, which in turn may promote or inhibit behavioral performance.

Behavioral factors can be promoted or inhibited and therefore, behavior, norms, and control have functions in the TPB. First, the sum of behavioral, normative, and control beliefs are indirect measures of attitude, subjective norms, and perceived behavioral control. These three factors further affect decision-making regarding the expected intentions of interviewed farmers. In addition, expected behaviors, norms, and control beliefs promote intentional attitudes, subjective norms, and perceived behavioral control through the formation of decision-making intentions and final decision behavior (Borges et al., 2014).

In the last 10 years, ecological and food safety concerns have markedly affected the production of high value agricultural products. Whether farmers' concern for these two factors affects their decision to adopt ESA is another focus of this article. This study explored whether the key factors of the TPB influence farmers' decisions regarding safe and environmentally friendly farming. Possible considerations in behavioral beliefs and concerns include increasing total production and product value, improving product quality, reducing manual input and material costs through precision fertilization, preventing soil erosion through precision irrigation management, and controlling farming procedures by receiving technological recommendations through their mobile phones. Possible factors for the normative beliefs aspect include government financial subsidies, professional counseling services, technological farming expansion, online stories of success, and support from family, neighbors, and friends. Adequate investment funds, professional and feasible levels of knowledge, and awareness of market access and marketing management are considered under the behavioral control category.

\section{Partial least squares structural equation modeling}

A structural equation modeling approach is effective for analyzing the causal relationship between indicator and latent variables (Ajzen, 2002a, b; Bamberg et al., 2003; Grabowski and Kerr, 2014; Han et al., 2010; Luhmann and Theuvsen, 2016) and the structural pathways of the TPB to measure related business behaviors (Bamberg et al., 2003; Borges et al., 2014; Han et al., 2010; Lalani et al., 2016; Senger et al., 2017b). With the convenience of fewer samples and no need to set sample distribution patterns in modeling (Hair et al., 2018), variance-based partial least squares structural equation modeling (PLS-SEM) provides a less restrictive exploration tool in the social sciences, and it is advantageous for its estimation of the potential values of observed variables (Chin, 2010; Hair et al., 2012; Henseler et al., 2009, 2015; Wold, 1975). This article comprises a prediction-oriented exploratory analysis on the effects of environmental concerns and product quality on farming technology behavior, using PLS-SEM for analysis (Hair et al., 2017a).

PLS-SEM consists of two models, namely the measurement and the structural model (Hair et al., 2019). For the measurement model, the reliability of the internal indicators and facets must be evaluated. First, the standardized factor loading must exceed a threshold of 0.7 in the internal consistency reliability analysis (Hair et al., 2012; Hulland, 1999). Second, the conventional indicator, Cronbach's $\alpha$, must be greater than 0.7 . Finally, the reliability test between the potential variables and the 
observed variables requires a consideration of their composite reliability (Bagozzi and Yi, 1988), for which a value of $\geq 0.7$ is acceptable (Fornell and Larcker, 1981; Hair et al., 2018).

The validity of the PLS-SEM model was measured using convergent and discriminant validity (Hair et al., 2016a). Convergent validity evaluates the average variance extracted (AVE) across all indicators with a specific construct. According to relevant research recommendations, the AVE across all potential indicators should exceed 0.5 (Bagozzi and Yi, 1988; Fornell and Larcker, 1981; Hair et al., 2006). This study used the Fornell-Larcker criterion (Fornell and Larcker, 1981; Götz et al., 2010) and the heterotrait-monotrait ratio (HTMT; Chin, 2010; Henseler et al., 2015; Rasoolimanesh et al., 2017) of correlations to indicate and assess discriminant validity (Hair et al., 2016a, b).

Path coefficients between facets were estimated using the bootstrap method (Dijkstra and Henseler, 2015). In total, 3,000 calculations were performed, and the statistical significance and explanatory power (R2) for hypothetical paths were estimated and examined (Hair et al., 2011).

\section{Construct development and variables}

Tea trees grow on hillsides; thus, soil management, such as water and soil conservation, is critical to tea farming in Taiwan. In recent years, consumers have begun to pay attention to the domestic tea they consume and whether tea plantations meet environmental and quality standards. New farming applications must ensure profitability by achieving lower costs or higher production; farmers, especially those with small-scale, lower-income plots, adopt new technology primarily for this reason (Lalani et al., 2016; Lee et al., 2016; Nguyen et al., 2019). Respondents measured their degree of agreement with statements on a 7-point Likert scale for each question. The major construct in this research was divided into two parts. First, the farmer's concern for ecology (EC) and product quality (QC) was included in terms of whether the farming management considers the effects on the environment and biodiversity and whether this ecological concern affects the quality requirements of products; then the effects of QC on AT, SN, and PBC were extended within the TPB model. Second, the structure of the TPB was emphasized by examining the influence of AT, SN, and PBC and analyzing how these three facets affect farmers' intention (IA) to adopt ESA. The relevant variables are listed in Table 1 .

\section{Structural model and path analysis}

The relationship between the research structure and the causal path is based on the two-stage reference TPB model proposed by Ajzen (1991). The first stage confirms the effects of EC on QC (Kim et al., 2014) with hypothesis 1 (H1), and the effect of QC on the TPB three-pillar facet is examined through a review of hypotheses 2 to $4(\mathrm{H} 2, \mathrm{H} 3$, and H4) (McFadden and Huffman, 2017; Valeeva et al., 2004). The second stage then analyzes the effects of the three facets on each other and then on the behavioral intentions (IA) of farming decision-makers using the ESA system as hypotheses 5 to 9, which display as $\mathrm{H} 5, \mathrm{H} 6, \mathrm{H} 7, \mathrm{H} 8$, and $\mathrm{H} 9$.

In addition, many studies have adopted a multigroup analysis of partial least squares according to categorical variables to more accurately target the socioeconomic conditions of the respondents. However, decision-makers may be affected by other 
unobservable heterogeneous attributes (Hair et al., 2016b). Therefore, the procedures do not include critical influencing factors, which may affect the validity of the inference. This study used the FIMIX-PLS approach (Hair et al., 2016a, b; Sarstedt and Ringle, 2010; Sarstedt et al., 2017) to examine the differences in the behaviors of tea farmers in different clusters by considering the characteristics of ESA (Hahn et al., 2002; Rigdon et al., 2011).

Table 1. Research constructs and questionnaire items. (Source: this study)

\begin{tabular}{|c|c|}
\hline Late & Descriptive definition and items \\
\hline $\begin{array}{l}\text { Ecological concerns } \\
\text { (EC) }\end{array}$ & $\begin{array}{l}\text { For me, caring for the environment and ecology is an attitude that must be valued } \\
\text { and considered in agricultural management (Kim et al., 2014). } \\
\text { - An eco-friendly management model (EFMM) to manage tea farms can assist in } \\
\text { the control and effective use of soil and water resources to protect the } \\
\text { environment. } \\
\text { - Tea farms can be managed with EFMMs, which can sustain coexistence with } \\
\text { surrounding flora and fauna. }\end{array}$ \\
\hline $\begin{array}{r}\text { Quality c } \\
\text { (Q }\end{array}$ & $\begin{array}{l}\text { For me, the quality improvements in tea products that occur after adopting an } \\
\text { EFMM will affect my decision-making attitude toward the system (McFadden and } \\
\text { Huffman, 2017; Valeeva et al., 2004). } \\
\text { - Using an EFMM to manage the tea farm can ensure the quality of the tea and the } \\
\text { peace of mind of the customers. } \\
\text { Using an EFMM to manage the tea farm can ensure the stability of tea quality } \\
\text { and enhance the level of tea production. }\end{array}$ \\
\hline $\begin{array}{r}\text { Attit } \\
\text { be }\end{array}$ & $\begin{array}{l}\text { Environment-smart agriculture (ESA) systems represent one popular local EFMM } \\
\text { application. For me, adopting an ESA system to manage the tea farm would be a } \\
\text { unique and comfortable decision. } \\
\text { - Therefore, considering the factors of "increasing the quantity of tea leaves } \\
\text { harvested," "upgrading tea leaf quality," "saving labor," "performing precision } \\
\text { fertilization," "mastering irrigation timing and precise water use," and "acquiring } \\
\text { timely management suggestions" constitute my attitude toward implementing the } \\
\text { ESA system. }\end{array}$ \\
\hline Subjecti & $\begin{array}{l}\text { Most of the people I care about will support and encourage my subsequent } \\
\text { adoption of the ESA system to manage the tea farm. } \\
\text { - Considerations such as "government grants," "agricultural organization and } \\
\text { counseling promotion," "technology promotion," "successful experiences of the } \\
\text { online community," and "recommendations of family, neighbors, or friends" will } \\
\text { constitute the normative nature of my belief in adopting the ESA system. }\end{array}$ \\
\hline $\begin{array}{l}\text { Perceived behavioral } \\
\text { control }(\mathrm{PBC})\end{array}$ & $\begin{array}{l}\text { For me, it is easy to manage my tea farm using an ESA system with the following } \\
\text { conditions: } \\
\text { " "Expertise in research and development," "operating capabilities of professional } \\
\text { machinery and facilities," "sufficient funds," and "understanding of product } \\
\text { markets" instill confidence toward using the ESA system. }\end{array}$ \\
\hline $\begin{array}{l}\text { Intention to adopt } \\
\text { ESA (IA) }\end{array}$ & $\begin{array}{l}\text { I will adopt the ESA system to manage the tea farm to achieve and maintain } \\
\text { business goals. } \\
\text { - If the adoption of the ESA system can "increase the profitability of the tea } \\
\text { farm," "generate public benefits to the tea industry," "promote new farming } \\
\text { techniques," and "improve tea farm market visibility after adoption," my intention } \\
\text { to adopt the ESA system will be constituted. }\end{array}$ \\
\hline
\end{tabular}

The FIMIX-PLS method proposed by Hahn et al. (2002) has been primarily used to determine optimal grouping by investigating the presence of unobservable heterogeneity in data. The procedures allow for estimates of the model parameters and the number of 
classifications related to the interviewee. Furthermore, the method can evaluate the path model between different classifications according to its validity (Arenas-Gaitán et al., 2018; Hair et al., 2016a, b; Matthews et al., 2016). The statistical results from grouping characteristics can shape policy and managerial measures for improving the farming system and promoting the efficacy and expansion of tea operators in Taiwan.

\section{Data collection and analysis}

A total of 439 tea farmers in central Taiwan were interviewed between May and June 2019. The number of valid surveys was 253, with a completion rate of $57.6 \%$. Approximately $62.5 \%$ of the respondents were male, and $37.5 \%$ were female (Table 2). Their average age was 43 years, and nearly $80 \%$ of the farmers surveyed were between 31 and 60 years old. Compared with the current average age of 64 for farmers in Taiwan (DGBAS, 2017), the respondents were younger. In addition, $56.1 \%$ were university graduates and nearly $10 \%$ held master's degrees. Moreover, $56 \%$ of respondents were members of specialized tea organizations. Fewer than half of the farmers owned their tea farms; rather, most of them jointly owned or rented them. Approximately $40.3 \%$ reported that their tea farm provided more than half of their household income, indicating that nearly $60 \%$ of the interviewed operators maintain family economic stability through additional part-time work.

Table 2. Demographic description of participants $(n=253)$. (Source: computed by this study)

\begin{tabular}{c|c|c}
\hline Variables and characteristics & Frequency & Percentage (\%) \\
\hline Gender & \multicolumn{2}{|l}{} \\
\hline Male & 158 & 62.5 \\
Female & 95 & 37.5 \\
\hline Age & \multicolumn{2}{|l}{} \\
\hline Below 30 & 37 & 14.6 \\
31 40 & 91 & 36.0 \\
$\mathbf{4 1 ~ 5 0}$ & 61 & 24.1 \\
$\mathbf{5 1 ~ 6 0}$ & 50 & 19.8 \\
61 and above & 14 & 5.5 \\
\hline Education & \multicolumn{2}{|l}{} \\
\hline Junior high school diploma & 16 & 6.3 \\
Senior high school diploma & 70 & 27.7 \\
Bachelor's degree & 142 & 56.1 \\
Master's degree and above & 25 & 9.9 \\
\hline Member of professional organization & \multicolumn{2}{|l}{} \\
\hline Yes & 142 & 56.1 \\
No & 111 & 43.9 \\
\hline Ownership of the tea farm under operation & 124 & 49.0 \\
\hline Below and equal 50\% & 129 & 51.0 \\
Above 50\% & 151 & 59.7 \\
\hline Below and equal 50\% & 102 & 40.3 \\
\hline Above 50\% & \multicolumn{2}{|l}{} \\
\hline
\end{tabular}




\section{Results}

\section{Evaluation of the measurement model and TPB structural path}

Measurement indicators and textual descriptions of the research facets were developed after the relevant constructs of previous studies and tea industry practices were referenced; these facets are presented in Table 1. Cronbach's $\alpha$ for each index and the composite reliability value indicated that all latent variables had acceptable internal consistency and content reliability (Hair et al., 2012; Hulland, 1999). The statistical results demonstrate that the factor loadings of all indicators met the requirements (Table 3). For the testing of convergent validity, the AVE values of the seven latent variables satisfied the commonality analysis.

Table 3. Index details for measurement models, reliability, and convergent validity

\begin{tabular}{|c|c|c|c|c|}
\hline Construct factors and items & $\alpha$ & $\mathbf{C R}$ & AVE & Loading \\
\hline Ecological concerns (EC) & 0.848 & 0.929 & 0.868 & \\
\hline $\begin{array}{c}\text { Effective use of soil and water resources can protect the earth } \\
\text { Responsibility to maintain the sustainable coexistence of } \\
\text { surrounding flora and fauna }\end{array}$ & & & & $\begin{array}{l}0.936 \\
0.927\end{array}$ \\
\hline Quality concerns (QC) & 0.914 & 0.959 & 0.921 & \\
\hline $\begin{array}{l}\text { ESA can ensure the stability of tea quality and satisfy processing } \\
\text { requirements } \\
\text { ESA can ensure the safety of tea for customers to consume }\end{array}$ & & & & $\begin{array}{l}0.961 \\
0.959\end{array}$ \\
\hline Attitude toward using an environmental smart farming system (AT) & 0.932 & 0.947 & 0.747 & \\
\hline $\begin{array}{l}\text { I can master the timing and irrigation of tea farms using the precise } \\
\text { amount of water }\end{array}$ & & & & 0.898 \\
\hline I can apply fertilizers systematically, effectively, and accurately & & & & 0.886 \\
\hline I can improve the quality of the tea & & & & 0.872 \\
\hline $\begin{array}{l}\text { I can monitor tea tree growth by using mobile phones and obtain } \\
\text { farming recommendations }\end{array}$ & & & & 0.866 \\
\hline I can increase the amount of tea leaves harvested & & & & 0.859 \\
\hline I can hire fewer workers and reduce workforce demands & & & & 0.804 \\
\hline Subjective norms (SN) & 0.868 & 0.906 & 0.66 & \\
\hline Counseling and promotion by professional technical units & & & & 0.884 \\
\hline Counseling and promotion by local agricultural organizations & & & & 0.863 \\
\hline Financial support from government subsidies & & & & 0.820 \\
\hline Success stories from online social media & & & & 0.804 \\
\hline Suggestions from family, neighbors, or friends & & & & 0.673 \\
\hline Perceived behavioral control (PBC) & 0.901 & 0.931 & 0.772 & \\
\hline Individuals must have sufficient knowledge of the system & & & & 0.923 \\
\hline Machine operation and facility requirements & & & & 0.878 \\
\hline Sufficient funds & & & & 0.868 \\
\hline Must increase market visibility of product & & & & 0.845 \\
\hline Intention to adopt ESA (IA) & 0.89 & 0.924 & 0.753 & \\
\hline Adopting ESA can be considered a new technological improvement & & & & 0.904 \\
\hline $\begin{array}{l}\text { Using ESA can generate public benefits that are also beneficial to } \\
\text { the tea industry }\end{array}$ & & & & 0.897 \\
\hline $\begin{array}{c}\text { Introducing ESA can be used as advertising to increase product } \\
\text { popularity }\end{array}$ & & & & 0.863 \\
\hline Using ESA can increase the profitability of the tea farm & & & & 0.804 \\
\hline
\end{tabular}

Alpha: Cronbach's $\alpha$; CR: composite reliability; AVE: average variance extracted 
The Fornell-Larcker criterion and the HTMT test of each primary construct exhibited significant differences in the paths of the model, indicating discriminant validity (Table 4). These statistical results indicated that the TPB framework and the potential paths between the primary constructs are appropriate for subsequent analysis with ecological and product quality concerns (Hair et al., 2017b, 2019).

Table 4. Discriminant validity of constructs

\begin{tabular}{c|c|c|c|c|c|c|c|c|c|c|c}
\hline \multirow{2}{*}{ Constructs } & \multicolumn{9}{|c|}{ Fornell-Larcker criterion } & \multicolumn{5}{|c}{ Heterotrait-Monotrait ratio (HTMT) } \\
\cline { 2 - 11 } & EC & QC & AT & SN & PBC & IA & EC & QC & AT & SN & PBC \\
\hline EC & 0.932 & & & & & & & & & & \\
QC & 0.842 & 0.96 & & & & & 0.955 & & & & \\
AT & 0.522 & 0.574 & 0.864 & & & & 0.586 & 0.62 & & & \\
SN & 0.408 & 0.431 & 0.437 & 0.812 & & & 0.476 & 0.485 & 0.487 & & \\
PBC & 0.434 & 0.432 & 0.356 & 0.583 & 0.879 & & 0.492 & 0.473 & 0.386 & 0.658 & \\
IA & 0.865 & 0.854 & 0.526 & 0.483 & 0.501 & 0.868 & 0.993 & 0.944 & 0.573 & 0.552 & 0.557 \\
\hline
\end{tabular}

EC: ecological concerns; QC: quality concerns; AT: attitude toward the behavior; SN: subjective norms; PBC: perceived behavioral control; IA: intention to adopt ESA

This study examined nine paths between EC, AT, SN, and PBC and the interactions among three primary constructs based on the TPB framework in Figure 2. The values of determinant coefficients between the major facets are listed in Table 5. The total effects of the major constructs were statistically significant $(\mathrm{P}<0.05)$; therefore, the simulation results determined that the TPB structure was significantly supported by the statistical results. The findings revealed that farmers' concerns for the conservation of soil and water resources alters their attitudes toward the quality of their own tea products $(\mathrm{H} 1$ : $\mathrm{EC} \rightarrow \mathrm{QC}, 0.842)$. Furthermore, concerns about tea quality affect the constructs of advantage evaluation $(\mathrm{H} 2: \mathrm{QC} \rightarrow \mathrm{AT}, 0.516)$, perceived expectations of others (H3: $\mathrm{QC} \rightarrow \mathrm{SN}, 0.220$ ), and self-perception and perceived ability to enact the system (H4: $\mathrm{QC} \rightarrow$ PBC, 0.432; see Fig. 3). All three constructs appreciably affected the intentions of the interviewed farmers to enact a new system $(\mathrm{H} 7: \mathrm{AT} \rightarrow \mathrm{IA}, 0.354 ; \mathrm{H} 8: \mathrm{SN} \rightarrow \mathrm{IA}$, 0.167; H9: PBC $\rightarrow$ IA, 0.278). Each path of the first group was significantly supported, demonstrating that the three fundamental constructs influence farmers' willingness to adopt an ESA system.

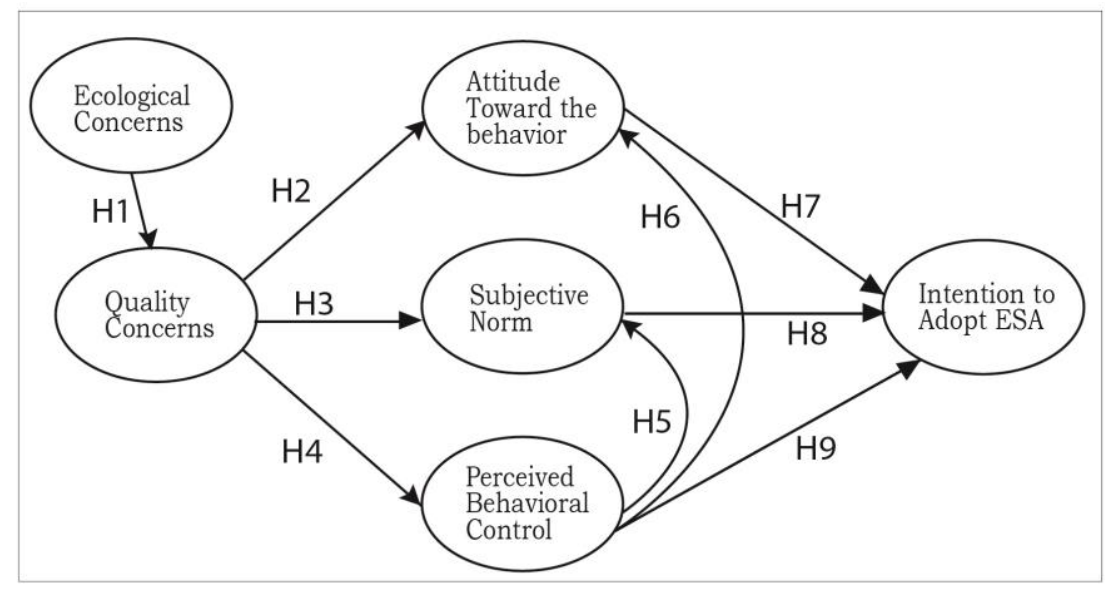

Figure 2. Proposed research framework 
Table 5. Path coefficients of the structural model

\begin{tabular}{c|c|c|c|c|c}
\hline Construct hypothesis and path & Path coef. & T statistics & P values & Result & $\mathbf{R}^{2}$-adj \\
\hline $\mathrm{H} 1: \mathrm{EC} \rightarrow \mathrm{QC}$ & 0.842 & 27.367 & $* *$ & Accepted & \\
$\mathrm{H} 2: \mathrm{QC} \rightarrow \mathrm{AT}$ & 0.516 & 5.913 & $* *$ & Accepted & \\
$\mathrm{H} 3: \mathrm{QC} \rightarrow \mathrm{SN}$ & 0.220 & 2.867 & $* *$ & Accepted & \\
$\mathrm{H} 4: \mathrm{QC} \rightarrow \mathrm{PBC}$ & 0.432 & 5.563 & $* *$ & Accepted & \\
$\mathrm{H} 5: \mathrm{PBC} \rightarrow \mathrm{SN}$ & 0.488 & 5.936 & $* *$ & Accepted & \\
$\mathrm{H} 6: \mathrm{PBC} \rightarrow \mathrm{AT}$ & 0.133 & 1.443 & & Rejected & \\
\hline TPB & & & & & \\
\hline $\mathrm{H} 7: \mathrm{AT} \rightarrow \mathrm{IA}$ & 0.354 & 4.276 & $* *$ & Accepted & \\
$\mathrm{H} 8: \mathrm{SN} \rightarrow \mathrm{IA}$ & 0.167 & 2.011 & $*$ & Accepted & \\
H9: $\mathrm{PBC} \rightarrow \mathrm{IA}$ & 0.278 & 3.935 & $* *$ & Accepted & \\
\hline Determinant coefficients for the construct & & & & & \\
\hline $\mathrm{QC}$ & & & & & 0.708 \\
$\mathrm{AT}$ & & & & & 0.338 \\
$\mathrm{SN}$ & & & & & 0.374 \\
$\mathrm{PBC}$ & & & & & 0.184 \\
$\mathrm{IA}$ & & & & & 0.399 \\
\hline
\end{tabular}

EC: ecological concerns; QC: quality concerns; AT: attitude toward the behavior; SN: subjective norms; PBC: perceived behavioral control; IA: intention to adopt ESA. *P $<0.05$, **P $<0.01$

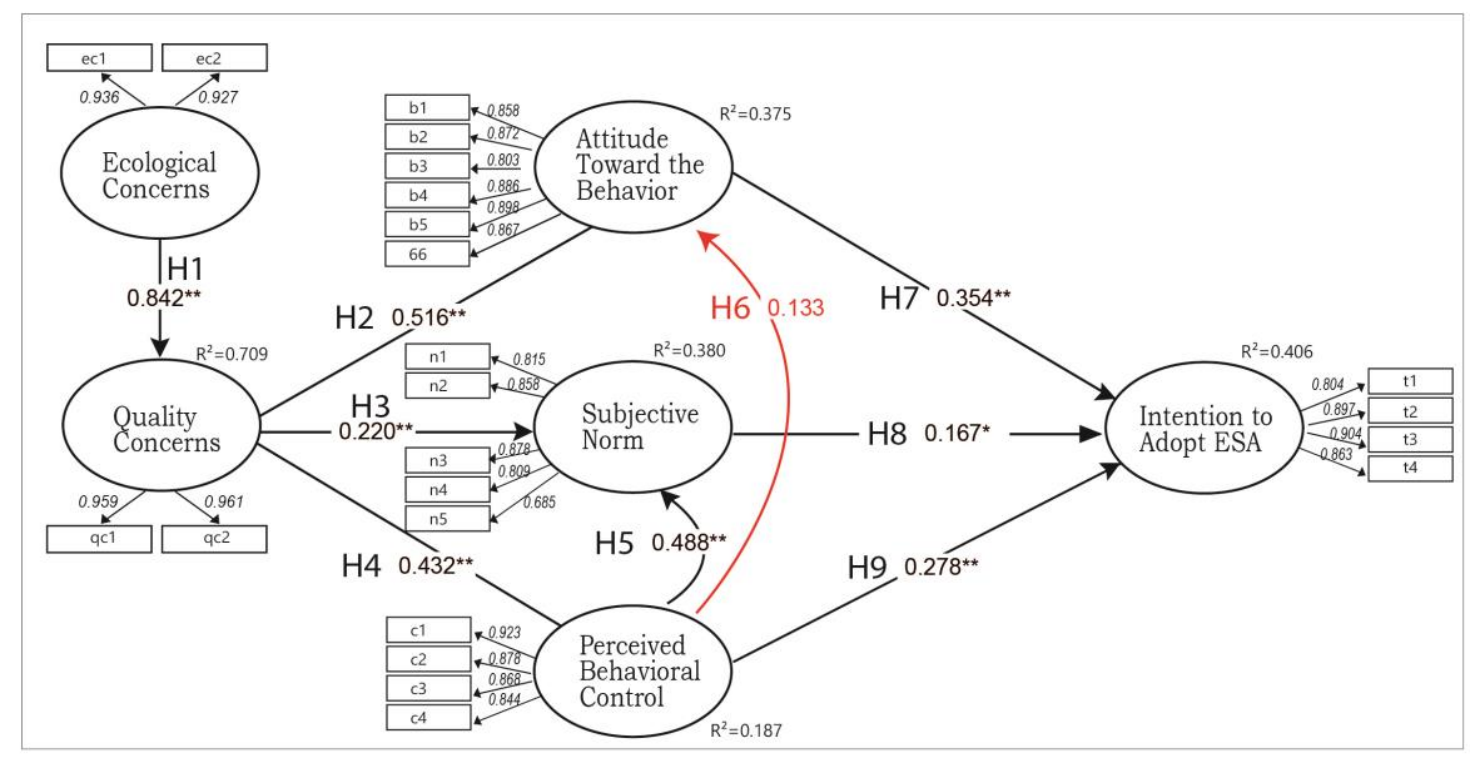

Figure 3. PLS path modeling results. Note: Red line indicates the path with no significance

Further analysis of the specific behavioral connotations was undertaken after the FIMIX-PLS grouping. This study used the $\mathrm{K}$ group verification indicators provided by Sarstedt et al. (2011) to examine potential unobservable heterogeneity in the data. Table 6 presents the analysis results of $\mathrm{K}$ from 2 to 5 and four classification critera, include modified Akaike's information criterion with factor 3 ( $\left.\mathrm{AIC}_{3}\right)$, Bayesian information criterion (BIC), consistent Akaike's information criterion (CAIC), 
minimum description length with factor 5 (MDL5) (Groß, 2018; Hair et al., 2017a, b; Sarstedt et al., 2011). Many studies have proposed the entropy statistic (EN) to demonstrate the maximum value for the most significant separation between groups, and it can be used as the determinant of the classification number (Groß, 2018; Hair et al., 2017a, b). This study used $\mathrm{K}=2$ as the basis for classification to avoid parameter estimation bias for the path coefficient because of the small sample number (Hair et al., $2017 \mathrm{a}, \mathrm{b})$. Therefore, the sample was divided into two groups according to the highest EN results of $132(52 \%)$ and $121(48 \%)$.

Table 6. Classification criteria for varying numbers of segments

\begin{tabular}{c|c|c|c|c|c}
\hline \multirow{2}{*}{ Criteria } & \multicolumn{5}{c}{ No. of segments (k) } \\
\cline { 2 - 6 } & Complete & $\mathbf{k = 2}$ & $\mathbf{k = 3}$ & $\mathbf{k = 4}$ & $\mathbf{k}=\mathbf{5}$ \\
\hline AIC $_{3}$ & 2908.62 & 2095.74 & 1955.99 & 1583.49 & 1574.99 \\
BIC & 2944.09 & 2169.21 & 2067.46 & 1732.96 & 1762.46 \\
CAIC & 2958.09 & 2198.21 & 2111.46 & 1791.96 & 1836.46 \\
MDL5 & 3253.96 & 2811.08 & 3041.34 & 3038.84 & 3400.34 \\
LnL & -1433.31 & -1004.37 & -912.00 & -703.25 & -676.50 \\
EN & & 0.92 & 0.91 & 0.90 & 0.92 \\
\hline Relative segment size & & & & & 0.40 \\
\hline group & 1.00 & 0.52 & 0.52 & 0.52 & 0.40 \\
group & & 0.48 & 0.40 & 0.26 & 0.27 \\
group & & & 0.08 & 0.12 & 0.15 \\
group & & & & 0.10 & 0.10 \\
\hline
\end{tabular}

$\mathrm{AIC}_{3}$ : modified AIC with factor 3; BIC: Bayesian information criterion; CAIC: consistent AIC; $\mathrm{MDL}_{5}$ : minimum description length with factor 5; LnL: log-likelihood; EN: entropy statistic (Normed)

The significance of the path coefficients of the two groups is detailed in Table 7. The results strongly indicated that the ecological concern of the farmers has an effect on achieving product quality, with significant coefficients for $\mathrm{H} 1 \quad(\mathrm{EC} \rightarrow \mathrm{QC})$ in both groups. EC and QC both significantly influenced the farmers' attitudes and their decision to adopt ESA for both groups.

An analysis of the influence of QC on facets of the model indicated that the three paths for the first group were all significant $(\mathrm{H} 2: \mathrm{QC} \rightarrow \mathrm{AT}=0.673 ; \mathrm{H} 3$ : $\mathrm{QC} \rightarrow \mathrm{SN}=0.584 ; \mathrm{H} 4: \mathrm{QC} \rightarrow \mathrm{PBC}=0.864)$, but the path of $\mathrm{QC}$ to AT was the only significant route for the second group. Three fundamental constructs influenced the farmers' willingness to adopt the ESA system for the first group, but attitude was the only factor affecting decision intention for the second group.

The effects of AT, SN, and PBC on IA were also supported; this supports the TPB model architecture and the connection between the concerns of EC and QC, which then affect AT, SN, PBC, and IA. The influence of EC on QC in the second group was less than that in the first group. For the overall TPB framework, the statistical results only supported the influence of QC on AT, and thus on IA, demonstrating that the EC and QC factors in this group only affect AT; AT to IA was the only significant path in the TPB framework. Farmers in this group were more concerned about what practical business results can be achieved using ESA. Unobserved variability was detected in the 
data; regrouping the tea farmers with different behaviors is therefore essential when considering their heterogeneity.

Table 7. Path coefficients and information for the two-segment solution

\begin{tabular}{|c|c|c|c|c|c|}
\hline Criteria & \multicolumn{2}{|c|}{$\begin{array}{c}\text { Segment } 1 \\
N=132(52 \%)\end{array}$} & \multicolumn{2}{|c|}{$\begin{array}{c}\text { Segment } 2 \\
\mathrm{~N}=121(48 \%)\end{array}$} & $\mathbf{t}[\mathbf{m g p}],\left|\Delta_{12}\right|$ \\
\hline \multicolumn{6}{|l|}{ Path coefficient } \\
\hline $\mathrm{H} 1: \mathrm{EC} \rightarrow \mathrm{QC}$ & \multicolumn{2}{|c|}{$1.000^{* *}$} & \multicolumn{2}{|c|}{$0.730^{* *}$} & $0.27 * *$ \\
\hline $\mathrm{H} 2: \mathrm{QC} \rightarrow \mathrm{AT}$ & \multicolumn{2}{|c|}{$0.673 * *$} & \multicolumn{2}{|c|}{$0.419^{* *}$} & 0.254 \\
\hline $\mathrm{H} 3: \mathrm{QC} \rightarrow \mathrm{SN}$ & \multicolumn{2}{|c|}{$0.584 * *$} & \multicolumn{2}{|c|}{0.101} & 0.483 \\
\hline $\mathrm{H} 4: \mathrm{QC} \rightarrow \mathrm{PBC}$ & \multicolumn{2}{|c|}{$0.864 * *$} & \multicolumn{2}{|c|}{0.107} & $0.757 * *$ \\
\hline $\mathrm{H} 5: \mathrm{PBC} \rightarrow \mathrm{SN}$ & \multicolumn{2}{|c|}{0.193} & \multicolumn{2}{|c|}{$0.463 * *$} & $0.27 * *$ \\
\hline $\mathrm{H6}: \mathrm{PBC} \rightarrow \mathrm{AT}$ & \multicolumn{2}{|c|}{0.092} & \multicolumn{2}{|c|}{0.058} & 0.034 \\
\hline \multicolumn{6}{|l|}{$T P B$} \\
\hline $\mathrm{H} 7: \mathrm{AT} \rightarrow \mathrm{IA}$ & \multirow{3}{*}{\multicolumn{2}{|c|}{$\begin{array}{c}0.179^{*} \\
0.163^{*} \\
0.682^{* *}\end{array}$}} & \multirow{3}{*}{\multicolumn{2}{|c|}{$\begin{array}{c}0.322 * \\
0.126 \\
0.077\end{array}$}} & 0.143 \\
\hline $\mathrm{H} 8: \mathrm{SN} \rightarrow \mathrm{IA}$ & & & & & 0.037 \\
\hline $\mathrm{H} 9: \mathrm{PBC} \rightarrow \mathrm{IA}$ & & & & & $0.605^{* *}$ \\
\hline \multirow{2}{*}{ Reliability and validity } & \multicolumn{2}{|c|}{ Segment 1} & \multicolumn{2}{|c|}{ Segment 2} & \\
\hline & $\mathrm{CR}_{1}$ & $\mathrm{AVE}_{1}$ & $\mathrm{CR}_{2}$ & $\mathrm{AVE}_{2}$ & \\
\hline $\mathrm{EC}$ & 0.983 & 0.967 & 0.892 & 0.806 & \\
\hline QC & 0.977 & 0.955 & 0.944 & 0.893 & \\
\hline AT & 0.949 & 0.755 & 0.943 & 0.733 & \\
\hline SN & 0.913 & 0.680 & 0.893 & 0.629 & \\
\hline PBC & 0.947 & 0.816 & 0.919 & 0.740 & \\
\hline IA & 0.945 & 0.810 & 0.904 & 0.703 & \\
\hline
\end{tabular}

EC: ecological concerns; QC: quality concerns; AT: attitude toward the behavior; SN: subjective norms; PBC: perceived behavioral control; IA: intention to adopt ESA; t[MGP] $\left|\Delta_{12}\right|$ : absolute difference between segment 1 and $2 ; \mathrm{t}=$ value for multigroup comparison test; $\mathrm{CR}_{\mathrm{i}}$ and $\mathrm{AVE}_{\mathrm{i}}$ : composite reliability and average variance extracted, respectively, for segment $i$, with $i=1,2$

The clustering analysis distinguished the influence of ecological and quality concerns on the respondents' intentions between groups by measuring the unobserved variables in the categories, indicating that the respondents were heterogeneous. Researchers can consider the factors influencing the decision to adopt ESA for different operators and subsequently develop more effective coaching and marketing strategies. Additionally, the concerns of all interviewed farmers in EC and QC significantly influenced their willingness to adopt ESA, indicating that environmental concern increases farmers' product quality demands, thereby increasing their willingness to implement ESA technology. During the early stages of the promotion and introduction of an ESA system, operators with higher EC and QC responsiveness exhibit a willingness to adopt; thus, promotional activities directed at such farmers would yield favorable results.

\section{Discussion}

An agricultural farming system oriented toward scale and production can lead to environmental, ecological, and safety problems, resulting in excess inputs of fertilizer 
and chemicals. With the adoption of an unknown farming system and input changes, framers may worry about the effects on tea quality and total yield. These considerations led to the development of environmentally friendly production systems that have become the focus of policy guidance (Daxini et al., 2019).

This study analyzed the data of 253 tea farmers in Taiwan to assess how ecological and product quality considerations affect their intentions to adopt a new system and their decision behavior within the TPB framework. This study was conducted with consideration for the high quality standards and the higher price for tea than for ordinary grains and horticultural crops in the market. This may encourage tea farmers located on hillsides with a sensitive soil environment to pay more attention to the development of new systems.

The results demonstrate that the TPB model is effective for analyzing the farmers' intention to adopt ESA and indicate that ecology and product quality concerns have positive effects on willingness to implement a new farming system. They also indicated that farmers who pay more attention to the environment and ecology may be more focused on product quality and thus more likely to adopt a new system. Through the monitoring of environmental factors such as soil and humidity through sensors and intelligent control, the application of ESA has indeed made significant changes to increase the yield of tea gardens and reduce management costs (Wu and $\mathrm{Ke}, 2020)$.

The study determined that ecological and quality concerns are associated with behavioral attitudes, subjective norms, and perceived behavioral control, which significantly affect adoption intention. The variables considered for each aspect exhibited the same reliability and validity, demonstrating that the questionnaire clearly presented the meaning of each potential concern. In summary, tea farmers with sensitive concerns in environment and product aspects will in turn affect their intent to adopt ESA. The validity and structure of the TPB model and its connections were supported by this study (Borges et al., 2014; Senger et al., 2017a, b; Issa and Hamm, 2017).

After FIMIX-PLS grouping, respondents were dividing into two groups with the specific behavioral connotations. If farmers concern on the environment and quality seriously, they also support the primary constructs in the TPB, such as self-expectation, social interactions, technical knowledge, communication patterns, and financial conditions, which in turn affect their willingness to adopt ESA.

The second group of farmers exhibited a relatively practical attitude toward considering ESA systems on their farms. Consultations with and support of the organizational network had less of an effect on their willingness to adopt, indicating that technical and financial support is not a large factor for consideration for these farmers.

The clustering result demonstrates that intention analysis must consider the heterogeneity of farmers' intentions (Hahn et al., 2002; Groß, 2018). This result provides statistical verification that the TPB indicators can be used to examine the intention of tea farmers, which can be used to adjust counseling measures. Understanding that tea farmers' different attitudes towards the environment and quality concerns will affect ESA application, differentiated strategies should be designed for different respondents to increase the adoption rate of the system.

\section{Conclusion}

This study demonstrated that both economic and noneconomic factors significantly influence farmers' intention to adopt ESA in lieu of their conventional farming systems. 
Farmers concerned about product safety and production stability achieve more market recognition, which increases their willingness to adopt new environmentally friendly systems.

We considered the effectiveness of economic incentives and the influence of social networks in the propagation of new ESA technology. These findings strongly support the role of local farmers' organizations and technical consulting units. However, information disseminated through online social networking affects farmers' decisionmaking more than does information shared by neighbors and nearby friends, who had minimal influence in this case. Opinions from the virtual network community are key sources of farming information.

The communication methods of professional advisory services have gradually developed in rural areas, indicating that policy interaction and knowledge communication must change. With the prevalence of online communities and the popularity of mobile devices, public-sector counseling services and marketing schemes, which usually depended on traditional interpersonal patterns, must adapt.

Strong and continual technical and financial support from local organizations is a key factor in enticing farmers to adopt a new environmentally friendly system. If profitability for tea farmers can be achieved and environmental and product quality concerns addressed to the satisfaction of public interest, farms with high-value-added products may be responsive to practicing environmentally-conscious farming.

This study analyzed the characteristics of tea farming, with a focus on the influence of unobservable factors affecting farmers' intention to adopt green technology instead of traditional socioeconomic-based systems. According to the results, concerns about the environment and product quality are highly influential aspects for the behavior of farmers in the high-value product market. The scope of system implementation can be extended by considering farmers' diversified responses toward greener farming technology. This study has successfully learned through the TPB model that tea farmers' decision to adopt ESA will be determined by their own concern about tea planting conditions and product quality. Therefore, a segmentation strategy should be adopted to promote high-interest groups for effective system application with consistent performance.

Acknowledgements. Authors are very grateful for the research funding provided by the Ministry of Science and Technology of Taiwan and the advice provided by Professor Shen Yuan from National Chung Hsing University of Taiwan during the project.

\section{REFERENCES}

[1] Ajzen, I. (1991): The theory of planned behavior. - Organizational Behavior and Human Decision Processes 50: 179-211.

[2] Ajzen, I. (2002a): Perceived behavioral control, self-efficacy, locus of control, and the theory of planned behavior. - Journal of Applied Social Psychology 32: 665-683.

[3] Ajzen, I. (2002b): Residual effects of past on later behavior: habituation and reasoned action perspectives. - Personality and Social Psychology Review 6: 107-122.

[4] Arenas-Gaitán, J., Rondán-Cataluña, F. J., Ramírez-Correa, P. E. (2018): Modelling the success of learning management systems: application of latent class segmentation using FIMIX-PLS. - Interactive Learning Environments 26: 135-147. 
[5] Bagozzi, R. P., Yi, Y. (1988): On the evaluation of structural equation models. - Journal of the Academy of Marketing Science 16: 74-94.

[6] Bamberg, S., Ajzen, I., Schmidt, P. (2003): Choice of travel mode in the theory of planned behavior: the roles of past behavior, habit, and reasoned action. - Basic and Applied Social Psychology 25: 175-187.

[7] Beedell, J., Rehman, T. (2000): Using social-psychology models to understand farmers' conservation behaviour. - Journal of Rural Studies 16: 117-127.

[8] Borges, J. A. R., Oude Lansink, A. G. J. M., Ribeiro, C. M., Lutke, V. (2014): Understanding farmers' intention to adopt improved natural grassland using the theory of planned behavior. - Livestock Science 169: 163-174.

[9] Borges, J. R. A., Oude Lansink, A. G. J. M. (2016): Identifying psychological factors that determine cattle farmers' intention to use improved natural grassland. - Journal of Environmental Psychology 45: 89-96.

[10] Brown, B., Llewellyn, R., Nuberg, I. (2018): Global learnings to inform the local adaptation of conservation agriculture in Eastern and Southern Africa. - Global Food Security 17: 213-220.

[11] Chin, W. W. (2010): How to Write Up and Report PLS Analyses. - In: Vinzi, V. E., Chin, W. W., Henseler, J., Wang, H. (eds.) Handbook of Partial Least Squares: Concepts, Methods and Applications. Springer, Berlin.

[12] Ciccullo, F., Pero, M., Caridi, M., Gosling, J., Purvis. L. (2018): Integrating the environmental and social sustainability pillars into the lean and agile supply chain management paradigms: a literature review and future research directions. - Journal of Cleaner Production 172: 2336-2350.

[13] Daxini, A., Ryan, M., O’Donoghue, C., Barnes, A. P. (2019): Understanding farmers' intentions to follow a nutrient management plan using the theory of planned behaviour. Land Use Policy 85: 428-437.

[14] Directorate General of Budget, Accounting and Statistics (DGBAS) (2017): Statistics of the 2015 census of agriculture in Taiwan. https://www.dgbas.gov.tw/public/Attachment/711301712205LGQ425T.pdf.

[15] Dijkstra, T. K., Henseler, J. (2015): Consistent partial least squares path modeling. - MIS Quarterly 39: 297-316.

[16] Fornell, C., Larcker, D. F. (1981): Evaluating structural equation models with unobservable variables and measurement error. - Journal of Marketing Research 18: 3950 .

[17] García, C. G. M., Dorward, P., Rehman, T. (2012): Farm and socio-economic characteristics of smallholder milk producers and their influence on technology adoption in Central Mexico. - Tropical Animal Health and Production 44: 1199-1211.

[18] Götz, O., Liehr-Gobbers, K., Krafft, M. (2010): Evaluation of Structural Equation Models Using the Partial Least Squares (PLS) Approach. - In: Vinzi, V. E., Chin, W. W., Henseler, J., Wang, H. (ed.) Handbook of Partial Least Squares: Concepts, Methods and Applications. Springer, Berlin.

[19] Grabowski, P. P., Kerr, J. M. (2014): Resource constraints and partial adoption of conservation agriculture by hand-hoe farmers in Mozambique. - International Journal of Agricultural Sustainability 12: 37-53.

[20] Groß, M. (2018): Heterogeneity in consumers' mobile shopping acceptance: a finite mixture partial least squares modelling approach for exploring and characterising different shopper segments. - Journal of Retailing and Consumer Services 40: 8-18.

[21] Hahn, C., Johnson, M. D., Herrmann, A., Huber, F. (2002): Capturing customer heterogeneity using a finite mixture PLS approach. - Schmalenbach Business Review 54: 243-269.

[22] Hair, J. F., Black, W. C., Babin, B. J., Anderson, R. E., Tatham, R. L. (2006): Multivariate Data Analysis. 6th Ed. - Prentice-Hall, New Jersey. 
[23] Hair, J. F., Ringle, C. M., Sarstedt, M. (2011): PLS-SEM: Indeed a silver bullet. - Journal of Marketing theory and Practice 19: 139-152.

[24] Hair, J. F., Sarstedt, M., Ringle, C. M., Mena, J. A. (2012): An assessment of the use of partial least squares structural equation modeling in marketing research. - Journal of the Academy of Marketing Science 40: 414-433.

[25] Hair, J. F., Hult, Y., Ringle, C., Sarstedt, M. (2016a): A Primer on Partial Least Squares Structural Equation Modeling (PLS-SEM). 2nd Ed. - Sage Publications, Thousand Oaks.

[26] Hair, J. F., Sarstedt, M., Matthews, L. M., Ringle, C. M. (2016b): Identifying and treating unobserved heterogeneity with FIMIX-PLS: Part I-method. - European Business Review 28: 63-76.

[27] Hair, J. F., Matthews, L. M., Matthews, R., Sarstedt, M. (2017a): PLS-SEM or CB-SEM: updated guidelines on which method to use. - International Journal of Multivariate Data Analysis 1: 107-123.

[28] Hair, J. F., Sarstedt, M., Ringle, C. M., Gudergan, S. P. (2017b): Advanced Issues in Partial Least Squares Structural Equation Modeling. - Sage Publications, Thousand Oaks.

[29] Hair, J. F., Black, W. C., Babin, B. J., Anderson, R. E. (2018): Multivariate Data Analysis. - Cengage Learing EMEA, London.

[30] Hair, J. F., Risher, J. J., Sarstedt, M., Ringle, C. M. (2019): When to use and how to report the results of PLS-SEM. - European Business Review 31: 2-24.

[31] Han, H., Hsu, L-T. J., Sheu, C. (2010): Application of the theory of planned behavior to green hotel choice: testing the effect of environmental friendly activities. - Tourism Management 31: 325-334.

[32] Henseler, J., Ringle, C. M. R., Sinkovics, R. R. (2009): The Use of Partial Least Squares Path Modeling in International Marketing. - In: Sinkovics, R. R., Ghauri, P. N. (eds.) New Challenges to International Marketing. Emerald Group Publishing Limited, Binley.

[33] Henseler, J., Ringle, C. M., Sarstedt, M. (2015): A new criterion for assessing discriminant validity in variance-based structural equation modeling. - Journal of the Academy of Marketing Science 43: 115-135.

[34] Hulland, J. (1999): Use of partial least squares (PLS) in strategic management research: a review of four recent studies. - Strategic Management Journal 20: 195-204.

[35] Issa, I., and Hamm, U. (2017): Adoption of organic farming as an opportunity for Syrian farmers of fresh fruit and vegetables: an application of the theory of planned behaviour and structural equation modelling. - Sustainability 9: 2024.

[36] Khatri-Chhetri, A., Aggarwal, P. K., Joshi, P. K., Vyas, S. (2017): Farmers' prioritization of Climate-Smart Agriculture (CSA) technologies. - Agricultural Systems 151: 184-191.

[37] Kim, Y. G., Jang, S. Y., Kim, A. K. J. (2014): Application of the theory of planned behavior to genetically modified foods: moderating effects of food technology neophobia. - Food Research International 62: 947-954.

[38] Lalani, B., Dorward, P., Holloway, G., Wauters, E. (2016): Smallholder farmers' motivations for using conservation agriculture and the roles of yield, labour and soil fertility in decision making. - Agricultural Systems 146: 80-90.

[39] Lalani, B., Dorward, P., Holloway, G. (2017): Farm-level economic analysis. Is conservation agriculture helping the poor? - Ecological Economics 141: 144-153.

[40] Lee, S., Nguyen, T. T., Poppenborg, P., Shin, H.-J., Koellner, T. (2016): Conventional, partially converted and environmentally friendly farming in South Korea: profitability and factors affecting farmers' choice. - Sustainability 8: 704.

[41] Liao, Y., and Xu, K. (2019): Traceability system of agricultural product based on blockchain and application in tea quality safety management. - Paper presented at the Journal of Physics: Conference Series 1288, the 5th Annual International Conference on Network and Information Systems for Computers (ICNISC2019), Wuhan, China.

[42] Luhmann, H., Theuvsen, L. (2016): Corporate social responsibility in agribusiness: literature review and future research directions. - Journal of Agricultural \& Environmental Ethics 29: 673-696. 
[43] Madden, T. J., Ellen, P. S., Ajzen, I. (1992): A comparison of the theory of planned behavior and the theory of reasoned action. - Personality and Social Psychology Bulletin 18: 3-9.

[44] Mahindarathne, P., Gunaratne, L. (2015): Entrepreneurial orientation of organic farmers: a case of organic vegetable farmers in the Badulla district of Sri Lanka. - Journal of International Food \& Agribusiness Marketing 27: 324-336.

[45] Makate, C., Makate, M., Mango, N., Siziba, S. (2019): Increasing resilience of smallholder farmers to climate change through multiple adoption of proven climate-smart agriculture innovations. Lessons from Southern Africa. - Journal of Environmental Management 231: 858-868.

[46] Matthews, L. M., Sarstedt, M., Hair, J. F., Ringle, C. M. (2016): Identifying and treating unobserved heterogeneity with FIMIX-PLS. - European Business Review 28: 208-224.

[47] McFadden, J. R., Huffman, W. E. (2017): Consumer valuation of information about food safety achieved using biotechnology: evidence from new potato products. - Food Policy 69: 82-96.

[48] Mittenzwei, K., Persson, T., Höglind, M., Kværnø, S. (2017): Combined effects of climate change and policy uncertainty on the agricultural sector in Norway. - Agricultural Systems 153: 118-126.

[49] Nguyen, A. T., Trinh, Q.-A., Pham, V. T., Le, B. B., Nguyen, D. T., Hoang, Q. N., Pham, H. T., Luu, V. N., Hens, L. (2019): Farmers' intention to climate change adaptation in agriculture in the red river delta biosphere reserve (Vietnam): a combination of Structural Equation Modeling (SEM) and Protection Motivation Theory (PMT). - Sustainability 11: 2993.

[50] Nkala, P., Mango, N., Zikhali, P. (2011): Conservation agriculture and livelihoods of smallholder farmers in Central Mozambique. - Journal of Sustainable Agriculture 35: 757-779.

[51] Osmond, D. L., Hoag, D. L., Luloff, A. E., Meals, D. W., Neas, K. (2015): Farmers' use of nutrient management: lessons from watershed case studies. - Journal of Environmental Quality 44: 382-390.

[52] Pannell, D. J., Llewellyn, R. S., Corbeels, M. (2014): The farm-level economics of conservation agriculture for resource-poor farmers. - Agriculture, Ecosystems \& Environment 187: 52-64.

[53] Pretty, J. (2008): Agricultural sustainability: concepts, principles and evidence. Philosophical Transactions of the Royal Society B: Biological Sciences 363: 447-465.

[54] Rahman, S. (2018): Environment-smart agriculture and mapping of interactions among environmental factors at the farm level: a directed graph approach. - Sustainability 10: 117.

[55] Rasoolimanesh, S. M., Ringle, C. M., Jaafar, M., Ramayah, T. (2017): Urban vs. rural destinations: residents' perceptions, community participation and support for tourism development. - Tourism Management 60: 147-158.

[56] Rigdon, E. E., Ringle, C. M., Sarstedt, M., Gudergan, S. P. (2011): Assessing Heterogeneity in Customer Satisfaction Studies: Across Industry Similarities and within Industry Differences. - In: Sarstedt, M., Schwaiger, M., Taylor, C. R. (eds.) Measurement and Research Methods in International Marketing. Emerald Group Publishing Limited, Bingley.

[57] Sarstedt, M., Ringle, C. M. (2010): Treating unobserved heterogeneity in PLS path modeling: a comparison of FIMIX-PLS with different data analysis strategies. - Journal of Applied Statistics 37: 1299-1318.

[58] Sarstedt, M., Becker, J.-M., Ringle, C. M., Schwaiger, M. (2011): Uncovering and treating unobserved heterogeneity with FIMIX-PLS: which model selection criterion provides an appropriate number of segments? - Schmalenbach Business Review 63: 3462. 
[59] Sarstedt, M., Ringle, C. M., Hair, J. F. (2017): Treating Unobserved Heterogeneity in PLS-SEM: A Multi-Method Approach. - In: Latan, H., Noonan, R. (eds.) Partial Least Squares Path Modeling. Springer International Publishing AG, Cham.

[60] Senger, I., Borges, J. A. R., Machado, J. A. D. (2017a): Using structural equation modeling to identify the psychological factors influencing dairy farmers' intention to diversify agricultural production. - Livestock Science 203: 97-105.

[61] Senger, I., Borges, J. A. R., Machado, J. A. D. (2017b): Using the theory of planned behavior to understand the intention of small farmers in diversifying their agricultural production. - Journal of Rural Studies 49: 32-40.

[62] Thornton, P. K., et al. (2018): A framework for priority-setting in climate smart agriculture research. - Agricultural Systems 167: 161-175.

[63] Valeeva, N. I., Meuwissen, M. P. M., Huirne, R. B. M. (2004): Economics of food safety in chains: a review of general principles. - NJAS-Wageningen Journal of Life Sciences 51: 369-390.

[64] Wall, P. C., Thierfelder, C., Ngwira, A., Govaerts, B., Nyagumbo, I., Baudron, F. (2013): Conservation agriculture in Eastern and Southern Africa. - In: Jat, R. A., Sahrawat, K. L., Kassam, A. H. (eds.) Conservation Agriculture Global Prospectives and Challenges. CAB International, Oxfordshire.

[65] Westermann, O., Förch, W., Thornton, P., Körner, J., Cramer, L., Campbell, B. (2018): Scaling up agricultural interventions: case studies of climate-smart agriculture. Agricultural Systems 165: 283-293.

[66] Wold, H. (1975): Path Models with Latent Variables: The NIPALS Approach. - In: Blalock, H. M., Aganbegian, A., Borodkin, F. M., Boudon, R., Capecchi, V. (eds.) Quantitative Sociology. Academic Press Inc, New York.

[67] Wu, M.-Y., and Ke, C.-K. (2020): Development and application of intelligent agricultural planting technology. The case of tea. - Paper presented at the 2020 International Symposium on Computer, Consumer and Control (IS3C), IEEE, Taiwan.

[68] Zeweld, W., Van Huylenbroeck, G., Tesfay, G., Speelman, S. (2017): Smallholder farmers' behavioural intentions towards sustainable agricultural practices. - Journal of Environmental Management 187: 71-81. 